\title{
Remove of Humic Acid From Water Using Magnetite Nanoparticles
}

\author{
F. Guey, M. Smiri, H. Chemingui, A. B. Dekhil, S. Elarbaoui, and A. Hafiane
}

\section{ABSTRACT}

Synthesis, characterization and utilization of iron oxide nanoparticles have been a subject of attention in recent years on the base of their interesting chemical and physics properties. Magnetite $\left(\mathrm{Fe}_{3} \mathrm{O}_{4}\right)$ nanoparticles were synthesed by chemical co-precipitation and characterized using $\mathbf{X}$ ray diffraction (XDR), Fourier transmission spectroscopy (FT-IR), dynamic light scattering and (DLS). $\mathrm{Fe}_{3} \mathrm{O}_{4}$ nanoparticles were successfully removed humic acid (HA) from water. The influence of $\mathrm{pH}$, contact time, adsorbent nanoparticle doses and $\mathrm{HA}$ concentrations were analyzed. Maximum HA removal occurred at pH 6 (89.63\%), 40 mg.L-1 of Magnetite (88.8\%), 0.03g of HA (96.64\%) and contact time of $20 \mathrm{~min}(\mathbf{9 4 . 3 7 \%})$. Sorption data fit pseudo-second order kinetics, indicated a chemical adsorption process. The Langmuir, Freundlich and Temkin adsorption isotherm models were applied to describe equilibrium data. Adsorption of HA on magnetite nanoparticles was well described by Temkin model. The maximum adsorption capacity was 128.23 mg.g-1. Fe3O4 nanoparticles were promising potential adsorbents for HA removal from water.

Keywords: Adsorption process; Co-precipitation; Humic acid; Iron oxide nanoparticles

Published Online: July 20, 2020.

ISSN: 2684-4478

DOI :10.24018/ ejchem.2020.1.4.9

F. Guey

Laboratory of Water, Membranes and Environment Biotechnology (LEMBE), Tunisia

(e-mail: beneynagueye93@ gmail.com) M. Smiri*

Shaqra University, College of Science and Arts - Sagir, Saudi Arabia

(e-mail: smirimoez ${ }^{@}$ yahoo.fr ) H. Chemingui

Laboratory of Water, Membranes and Environment Biotechnology (LEMBE), Tunisia

(e-mail: hajerchemingui2@gmail.com) A. B. Dekhil

Laboratory of Water, Membranes and Environment Biotechnology (LEMBE), Tunisia

(e-mail:alwaysoptimist20@gmail.com) S. Elarbaoui

Shaqra University, College of Science and Arts - Sagir, Saudi Arabia

(e-mail: soumaia.elarbaoui @ yahoo.fr)

A. Hafiane

Laboratory of Water, Membranes and

Environment Biotechnology

(LEMBE), Tunisia

(e-mail: amor_hafiane ${ }^{\circledR}$ yahoo.com)

*Corresponding Author

\section{INTRODUCTION}

Iron oxide nanoparticles have been previously described [1], [2]. Study reported different methods of synthesis of magnetite $\left(\mathrm{Fe}_{3} \mathrm{O}_{4}\right)$ nanoparticles such as co-precipitation [3], sol-gel [4], hydrothermal [5] and decomposition methods [6]. Co-precipitation is a suitable process to produce synthetic $\mathrm{Fe}_{3} \mathrm{O}_{4}$ nanoparticles, due to its high level of efficiency [7].

Magnetite $\left(\mathrm{Fe}_{3} \mathrm{O}_{4} 4\right)$ nanoparticles can support a diversity of applications including the development of scientific and technological functions [8]. In photocatalysis [9], biomedical [10] and adsorption for removal of heavy metals [11] or organic matters [12]. Natural humic acid (HA) are the most predominant reactive fractions of organic matter (NOM) that is present in water resources [12]. [13]. Humic acid (HA) consist of a complex polymer of carbonyl, phenolic, carboxyl and hydroxyl groups [14]. synthetic organic chemicals and trace element Humic can be and carry by HA through water treatment facilities and distribution systems [13].

Simultaneously, HA has disadvantageous effects on the taste and appearance water [15]. Mostsevere, humic acid (HA) can be react with chlorine during chlorination and produce strongly carcinogenic disinfection byproducts (DBPs) such as trihalomethanes (THMs) and haloacetic acids (HAAs) [16]. Thus, removing of humic acid (HA) in water treatment could be paramount and essential for environmental and health reasons.].

In this paper, we reported the preparation of magnetite nanoparticles, characterization and its application to remove humic acid (HA) from a synthetic water. We chose in this study the chemical Co-precipitation method to prepare the magnetite nanoparticles, the characterization with different techniques such as XDR, FT-IR, DLS and the application was realized by studying in detail the influence of various parameters such as solution $\mathrm{pH}$, contact time, solution $\mathrm{pH}$, 
adsorbate concentration and adsorbent dose. The adsorption procedure was also defined by kinetics and isotherm analysis.

\section{PROCEDURE}

\section{A. Materials}

Ferrous sulfate (FeSO4, 6H2O) and ferric nitrate $\left[\left(\mathrm{Fe}\left(\mathrm{NO}_{3}\right)_{3}\right]\right.$ were used as a source of $\mathrm{Fe}^{2+}$ and $\mathrm{Fe}^{3+}$ ions, respectively. Sodium hydroxide $(\mathrm{NaOH})$ was used as a base in the synthesis of magnetite nanoparticles. PVP was used as a stabilizer in solution phase. Humic acid (HA) used in this study was purchased from Sigma.

\section{B. Synthesis of magnetite nanoparticles}

Magnetite nanoparticles were synthesized follow B. Saha method [7] where we changed the triethyl amine by $\mathrm{NaOH}$ and the SDS by PVP.

\section{Characterization of magnetite (Fe3O4) nanoparticles}

Magnetite nanoparticles synthesized were defined by several techniques. The XRD analysis of magnetite nanoparticles was conducted on X'PERT Pro MPD PANALYTICAL with a $\mathrm{Cu} \mathrm{K} \alpha$ source $(\lambda=1.54056 \AA)$. FTIR spectra were recorded at $400-4000 \mathrm{~cm}-1$ using PerkinElmer spectrum (FTIR2000). The size distribution and zeta potential were obtained with a zetasizer (MALVERN, NanoZS). The morphology of the particular was obtained with a scanning electron micrographs (MEB).

\section{Adsorption experiments}

experiments of Adsorption were attended in triplicates and the results are reported as average. Adsorption experiments were conducted at various $\mathrm{pH}$ values, contact time, initial HA concentration and adsorbent dose. The solution $\mathrm{pH}$ was adjusted with 0.1 mo.1-1 $\mathrm{HCl}$ or $\mathrm{NaOH}$ solutions. Adsorption experiments were done in flaks containing $100 \mathrm{ml}$ of $\mathrm{HA}$ solution and $0.1 \mathrm{~g}$ of $\mathrm{Fe}_{3} \mathrm{O}_{4}$ at room temperature. After predetermined contact time, the aqueous solution was rapidly separated was by centrifugation and the residual concentration of HA in the supernatant was measured by a Perkin-Elmer UV-Vis spectrophometer (Lamda 25) at $260 \mathrm{~nm}$. The HA adsorption capacity of $\mathrm{Fe}_{3} \mathrm{O}_{4}$ at any time $\mathrm{t}$ (qt, mg.g-1) was calculated using the following equation :

$$
Q_{t}=\frac{(C O-C t) V}{m}
$$

where $\mathrm{CO}$ (mg.l-1) is the initial concentration of $\mathrm{HA}, \mathrm{Ct}$ (mg.1-1) is the instant concentration of HA at any time t, V (L) is the volume of the solution and $\mathrm{m}(\mathrm{g})$ is the mass of $\mathrm{Fe}_{3} \mathrm{O}_{4}$.

\section{RESULTS AND DISCUSSION}

The FT-IR spectrum (Figure 1) of magnetite (Fe3O4) nanoparticles shows that the characteristics peaks at $580 \mathrm{~cm}$ 1 relate to $\mathrm{Fe}-\mathrm{O}$ stretching vibration. The bands near 3200 $\mathrm{cm}-1$ and $1300 \mathrm{~cm}-1$ refer to the $\mathrm{O}-\mathrm{H}$ stretching vibration. The XRD patterns of magnetite nanoparticles samples are shown in Figure 2, which revealed the crystalline nature of magnetite nanoparticles. A series of characteristic peaks for magnetite $(\mathrm{Fe} 3 \mathrm{O} 4)\left(2 \Theta=30.15^{\circ}, 35.52^{\circ}, 47.17^{\circ}, 53.56^{\circ}\right.$, $58.23^{\circ}, 64.01^{\circ}$ ) were observed and corresponding the crystal planes of (220), (311), (400), (422), (511) and (440), respectively. These peaks are consistent with standard data for magnetite phase (ASTM 89-1397). The average crystallite size calculated using the Debye-Scherrer equation was found to be $44.14 \mathrm{~nm}$.

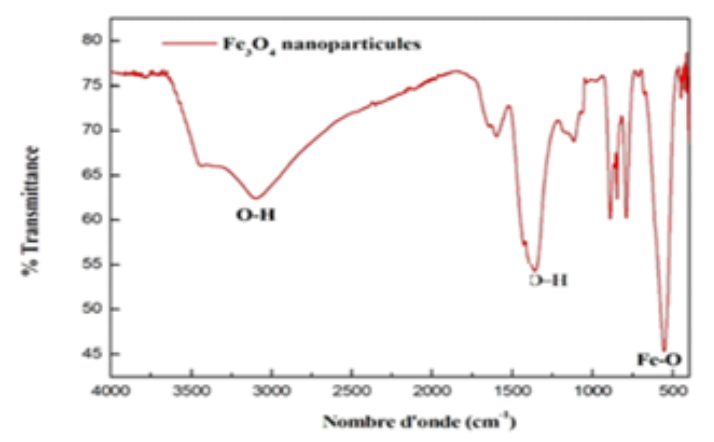

Fig. 1. FT-IR spectrum of magnetite $\left(\mathrm{Fe}_{3} \mathrm{O}_{4}\right)$.

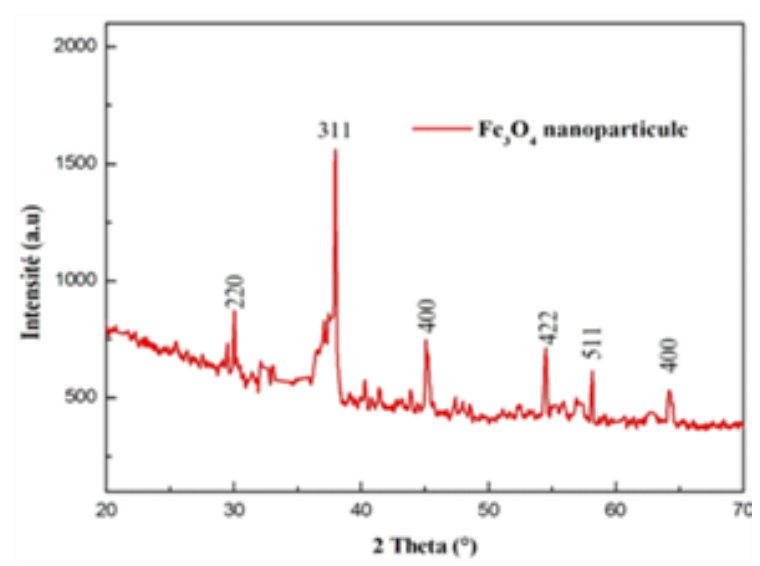

Fig. 2. XRD patterns of magnetite $\left(\mathrm{Fe}_{3} \mathrm{O}_{4}\right)$.

The uptake of $\mathrm{HA}$ by $\mathrm{Fe} 3 \mathrm{O} 4$ was studied over a $\mathrm{pH}$ range of 4-11 and results are given by Fig.3. The plot of Fig.1 shows a noticeable increase of HA uptake by $\mathrm{Fe} 3 \mathrm{O} 4$ from 11.97 to $26.88 \mathrm{mg}$. g- 1 when solution $\mathrm{pH}$ value shifts from 4 to 8 . After $\mathrm{pH}=8$, the HA uptake decreases slightly and while keeping an almost constant pace. This indicates that HA uptake onto Fe3O4 nanoparticles is Favorited at higher $\mathrm{pH}$ values. This may be due to the charges of HA molecules and $\mathrm{Fe} 3 \mathrm{O} 4$ nanoparticles [22].

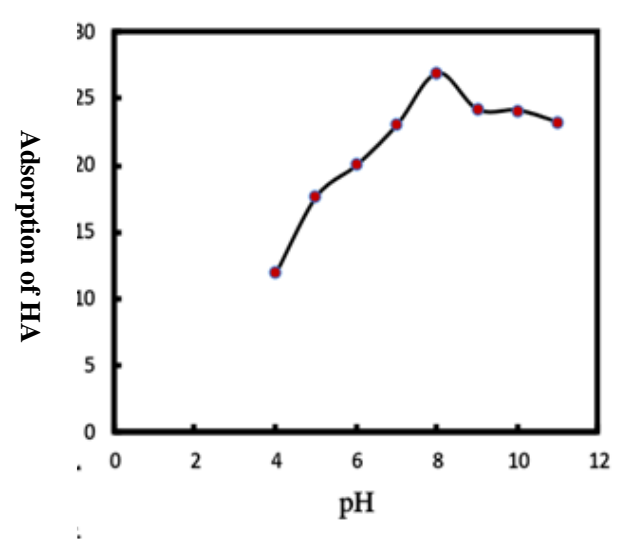

Fig. 3. Effect of solution $\mathrm{pH}$ on $\mathrm{HA}$ adsorption onto $\mathrm{Fe}_{3} \mathrm{O}_{4}$ (initial HA concentration $30 \mathrm{mg} / \mathrm{L}$, Room temperature, contact time $2 \mathrm{~h}$ ). 
The effect of adsorbent dose on adsorption of HA on $\mathrm{Fe}_{3} \mathrm{O}_{4}$ was investigated using different dose $0.01 \mathrm{~g}$ to $0.08 \mathrm{~g}$ and the results are showed in Fig.4. The adsorption capacity showed by Fig. 4 decrease with an increase in adsorbent dose and this is may be caused by the higher disponible of the exchangeable sites [23].

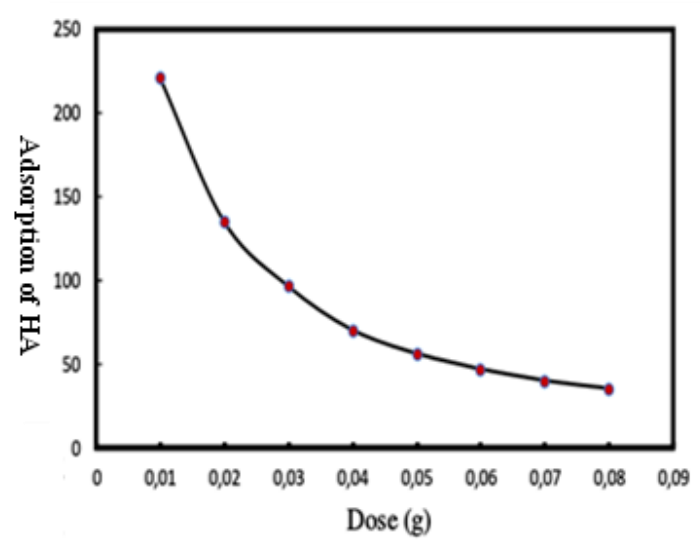

Fig. 4. Effect of adsorbent dose on adsorption of $\mathrm{HA}$ on $\mathrm{Fe}_{3} \mathrm{O}_{4}$ (initial HA concentration $30 \mathrm{mg} / \mathrm{L}$, solution $\mathrm{pH} 6$, contact time $2 \mathrm{~h}$ ).

The effect of initial HA concentration was carried out at 5-50 mg.L-1 as show in Fig. 5. It's well known that the initial concentration of adsorbate has almost always an effect on adsorption process. Indeed, the HA uptake onto $\mathrm{Fe} 3 \mathrm{O} 4$ increased as things progress the initial HA concentration increases. This may be related to an increase driving force, which permits more HA molecules to pass from the solution to the adsorbent surface [22].

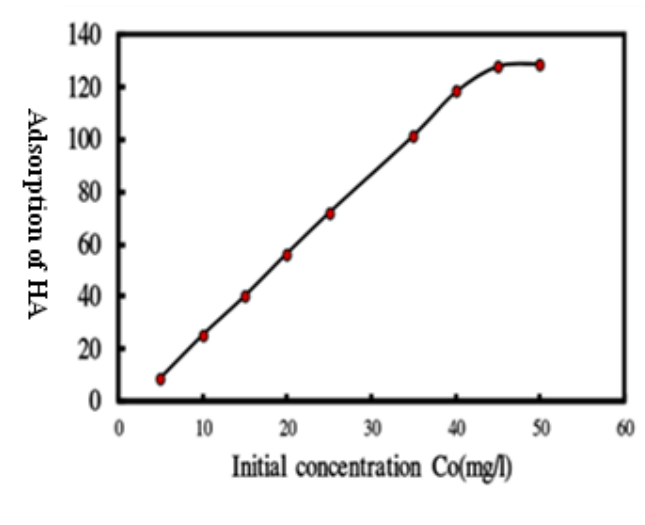

Fig. 5. Effect of initial HA concentration (solution $\mathrm{pH} 6$, contact time 2h, masse $0.03 \mathrm{~g}$ ).

The effect of contact time on adsorption of onto Fe3O4 was carried out at 5-70 min. The results are illustrated by Fig.6.

The Fig.6 shows two phases of HA uptake rate onto $\mathrm{Fe} 3 \mathrm{O} 4$. The first one occurred during the primary $20 \mathrm{~min}$ in which the absorption rate was elevated and the HA uptake reached the level of $80 \%$. This high rate can be explained by the presence of a high number of vacant sites on the adsorbent surface during the initial phase. The second phase began after the primary $20 \mathrm{~min}$ in which the HA uptake decreases slightly and tend to be constant after $30 \mathrm{~min}$. The constant rate implies that adsorption has reached an equilibrium state and this is can be explained by the presence of repulsive forces between HA molecules in the aqueous solution and those on the surface of Fe3O4 [24].

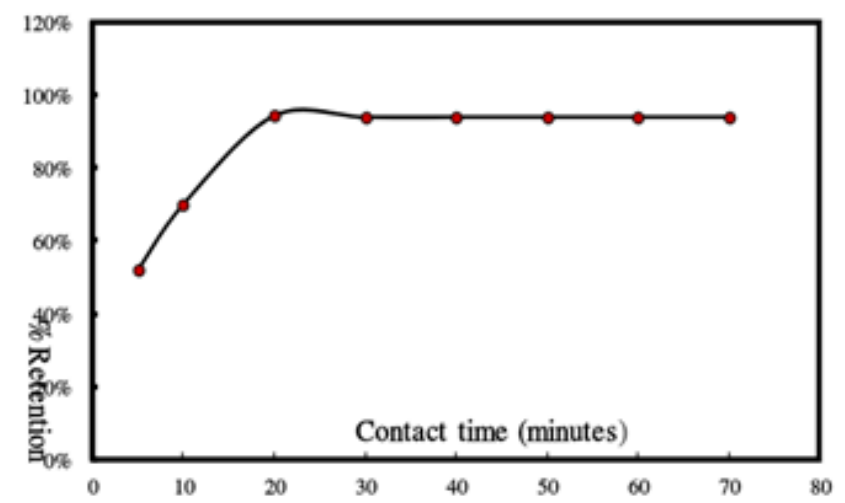

Fig. 6. Effect of contact on adsorption of $\mathrm{HA}$ onto $\mathrm{Fe}_{3} \mathrm{O}_{4}$ (solution $\mathrm{pH} 6$, adsorbent dose $0.03 \mathrm{~g}$ ).

In order to understand how the molecules of HA interact with the adsorbent at constant temperature, many adsorption isotherms were used. The well known of them, and which often used to better describe the equilibrium adsorption, is Langmuir, Freundlich and Temkin isotherm models [25]. The Langmuir isotherm model assumes monolayer adsorption onto a surface with a finite number of identical sites with no interaction between adsorbed molecules [26].

Langmuir model is represented as follows:

$$
Q_{e}=\frac{Q_{\max } K_{L} C_{e}}{1+K_{L} C_{e}}
$$

Where Qe is the amount of HA adsorbed per mass unit of $\mathrm{Fe} 3 \mathrm{O} 4$ at equilibrium (mg.g-1), $\mathrm{Ce}$ is the equilibrium concentration of remaining HA in the solution (mg.L-1), Qmax is the monolayer biosorption capacity of the biosorbent (mg.g-1) and KL is the Langmuir biosorption constant (L.mg-1).

The Linear form of isotherm can be presented as the following:

$$
\frac{C_{e}}{Q_{e}}=\frac{1}{K_{L} Q_{\max }}+\frac{C_{e}}{q_{\max }}
$$

The Langmuir isotherm of HA adsorption onto Fe3O4 is shown in Fig.7. The Freundlich adsorption isotherm is an empirical equation based on the adsorption on the heterogeneous surface as well as multilayer adsorption [27]. The nonlinear form of the Freundlich adsorption isotherm can be defined by the following equation:

$$
Q_{e}=K_{F} C_{e}^{\frac{1}{n}}
$$

The Freundlich isotherm constant $\mathrm{n}$ is an empirical parameter that varies with the degree of heterogeneity and $\mathrm{KF}$ is related to adsorption capacity. $\mathrm{KF}$ and $1 / \mathrm{n}$ values were determinate in using the linear form of Freundlich isotherm described by the following equation:

$$
\ln \left(\mathrm{q}_{\mathrm{e}}\right)=\ln \left(\mathrm{K}_{\mathrm{F}}\right)+1 / \mathrm{n} \ln \left(\mathrm{C}_{\mathrm{e}}\right)
$$




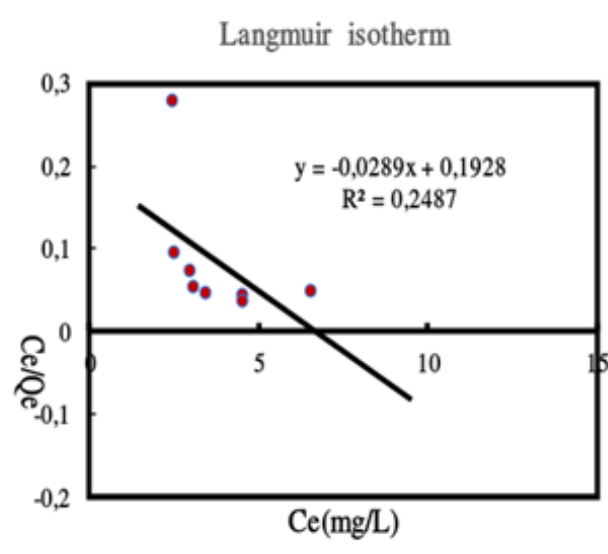

Fig. 7. Langmuir isotherm of HA adsorption onto $\mathrm{Fe}_{3} \mathrm{O}_{4}$.

The Freundlich isotherm of HA adsorption onto Fe3O4 is shown in Fig.8. The Temkin isotherm model is applicable to adsorption on heterogeneous surface as well as multilayer adsorption and characterized by a unit distribution of maximum attraction energy [28]. The Temkin equation is given as:

$$
Q_{e}=B \cdot \operatorname{Ln}\left(K_{T}\right)+B \cdot \operatorname{Ln}\left(C_{e}\right)
$$

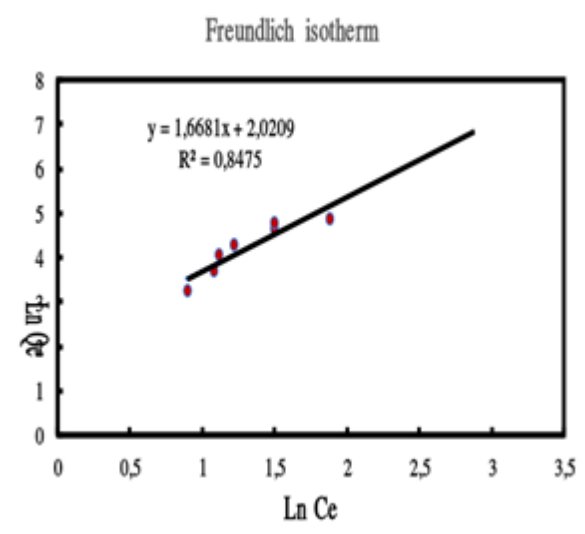

Fig. 8. Freundlich isotherm of HA adsorption onto $\mathrm{Fe}_{3} \mathrm{O}_{4}$.

Where $\mathrm{KT}$ is the Temkin constant (L.mg-1) and B is constant related to the adsorption heat. The Temkin isotherm of HA adsorption onto Fe3O4 is shown in Fig.9.

Temkin isotherm

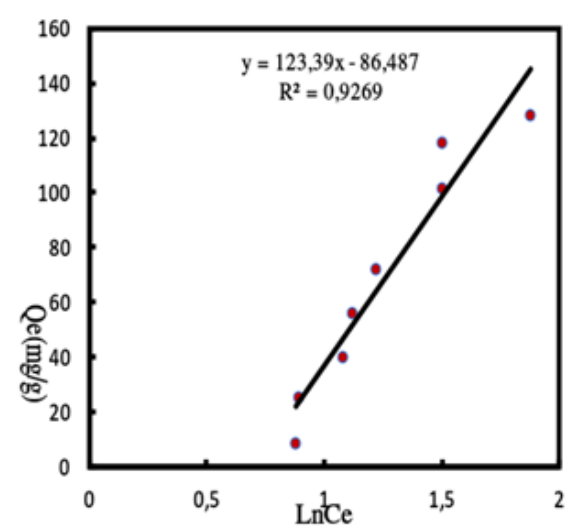

Fig. 9. Temkin isotherm of HA adsorption onto $\mathrm{Fe}_{3} \mathrm{O}_{4}$.

After analyzing the three isotherms, the fitting results presented by their correlation coefficient $\left(\mathrm{R}^{2}\right)$, showed that
HA adsorption process is better fitted by Temkin model than Langmuir or Freundlich models, indicating that adsorption of $\mathrm{HA}$ onto $\mathrm{Fe} 3 \mathrm{O} 4$ is multilayer.

In order to identify the kinetic rate-determining step (slowest step) of adsorption process, two kinetic models were used to fit the data including pseudo-first-order and pseudo-second-order models.

The pseudo-first-order [29] is presented as follows:

$$
Q_{t}=Q_{e}\left(1-e^{\left(-k_{1} \cdot t\right)}\right)
$$

Where qe and qt are the HA adsorption capacities for $\mathrm{Fe} 3 \mathrm{O} 4$ (mg.g-1) at equilibrium and any time t respectively; $\mathrm{k} 1$ is the rate constant of pseudo-first-order kinetic model (1.min-1). The pseudo-first-order model plots for HA adsorption onto Fe3O4 is shown in Fig.10.

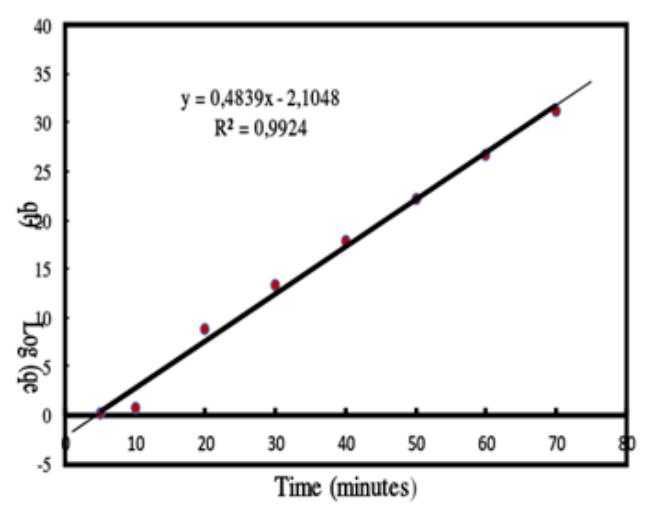

Fig. 10. Pseudo-first-order kinetic model plots for HA adsorption onto $\mathrm{Fe}_{3} \mathrm{O}_{4}$

The pseudo-second-order [30] is given as follows:

$$
\frac{t}{Q_{t}}=\frac{1}{k_{2} Q_{e}^{2}}+\frac{1}{Q_{e}}
$$

where $\mathrm{k}_{2}$ is the rate constant of pseudo-second-order kinetic model (g.(mg.min $\left.)^{-1}\right)$. The pseudo-second-order model plots for $\mathrm{HA}$ adsorption onto $\mathrm{Fe} 3 \mathrm{O} 4$ is shown in Fig.11.

Based on the correlation coefficients $\left(\mathrm{R}^{2}\right)$ values shown in Fig.10 and Fig.11, the pseudo-second-order kinetic model can be used to fit the adsorption process ranging the whole contact time field better than the pseudo-first-order kinetic model, indicating that the $\mathrm{HA}$ adsorption onto $\mathrm{Fe} 3 \mathrm{O} 4$ is a chemical adsorption [30].

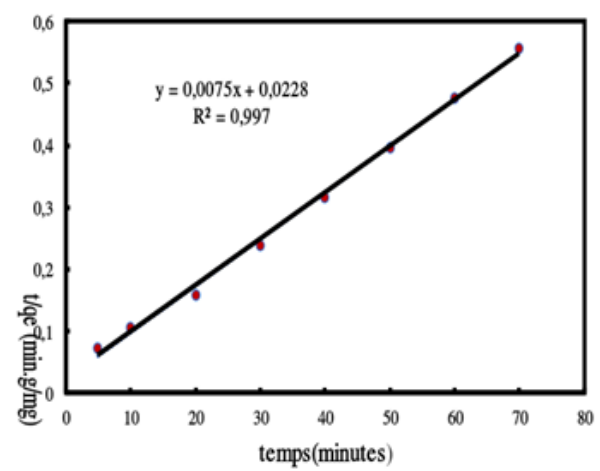

Fig. 11. Pseudo-second-order kinetic model plots for HA adsorption onto $\mathrm{Fe}_{3} \mathrm{O}_{4}$. 
The adsorption of $\mathrm{HA}$ onto $\mathrm{Fe} 3 \mathrm{O} 4$ was investigated at four different temperatures $\left(25^{\circ} \mathrm{C}, 35^{\circ} \mathrm{C}, 45^{\circ} \mathrm{C}\right.$ and $\left.55^{\circ} \mathrm{C}\right)$. The HA adsorption for $\mathrm{Fe}_{3} \mathrm{O}_{4}$ at equilibrium decreases when the temperature increase from $25^{\circ} \mathrm{C}$ to $55^{\circ} \mathrm{C}$, indicating better adsorption at lower temperature and an endothermic uptake process [31]. The values of thermodynamic parameters such as free energy $\left(\Delta \mathrm{G}^{\circ}\right)$, enthalpy $\left(\Delta \mathrm{H}^{\circ}\right)$ and entropy $\left(\Delta S^{\circ}\right)$ were determined using the following equations [32]:

$$
\begin{aligned}
\Delta G^{0} & =-R T \operatorname{Ln} K_{L} \\
L n K_{L} & =\frac{\Delta S^{0}}{R}-\frac{\Delta H^{0}}{R T}
\end{aligned}
$$

Where $\mathrm{K}_{\mathrm{L}}$ is the constant of equilibrium (ml.g ${ }^{-1}$ ) and equal to qe/Ce, $\mathrm{R}$ is the universal gas constant $(8.314$ $\left.\mathrm{J} .(\mathrm{mol} . \mathrm{K})^{-1}\right)$ and $\mathrm{T}$ is reaction temperature $(\mathrm{K})$. The values of $\Delta \mathrm{H}^{\circ}$ and $\Delta \mathrm{S}^{\circ}$ are obtained from the slope and intercept of the line plotted by $\mathrm{Ln}(\mathrm{KL})$ versus $1 / \mathrm{T}$, respectively (Fig.12).

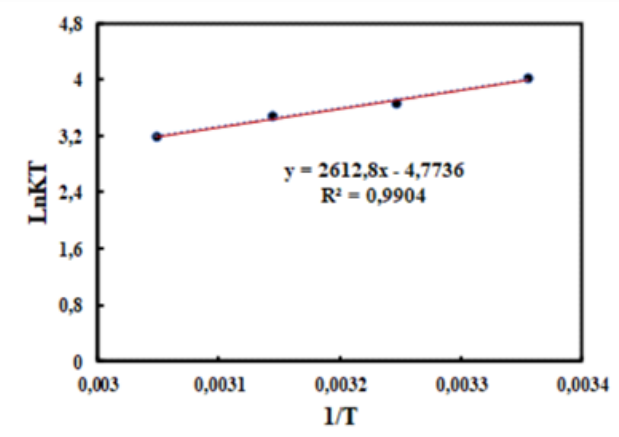

Fig. 12. LnKL versus 1/T.

The obtained thermodynamic parameters for the adsorption of HA onto $\mathrm{Fe} 3 \mathrm{O} 4$ are listed in table 1 and table 2.

TABLE 1: $\triangle \mathrm{G}$ VALUES.

\begin{tabular}{|l|l|l|l|l|l|l|}
\hline $\mathrm{T}\left(\mathrm{C}^{\circ}\right)$ & $\mathrm{T}(\mathrm{K})$ & $\mathrm{Co}(\mathrm{mg} / \mathrm{L})$ & $\mathrm{Cf}(\mathrm{mg} / \mathrm{L})$ & $\mathrm{Qe}$ & $\mathrm{Ln} \mathrm{K} \mathrm{L}$ & $\Delta \mathrm{G}(-\mathrm{RTLnK})$ \\
\hline 25 & 298 & 40 & 2.27 & 125.7666 & 4.014647977 & -3756.611501 \\
\hline 35 & 308 & 40 & 3.151 & 122.8300 & 3.663081423 & -3542.639306 \\
\hline 45 & 318 & 40 & 3.751 & 120.8300 & 3.472362128 & -3467.223032 \\
\hline 55 & 328 & 40 & 4.835 & 117.2166 & 3.188142376 & -3283.531596 \\
\hline
\end{tabular}

TABLE 2: $\Delta$ S AND $\Delta$ H VALUES.

\begin{tabular}{|l|l|}
\hline$\Delta \mathrm{H}(\mathrm{J} / \mathrm{mole})$ & $\Delta \mathrm{S}(\mathrm{J} /$ mole. $\mathrm{K})$ \\
\hline$-21722,819$ & $-39,687$ \\
\hline
\end{tabular}

The negative values of $\Delta \mathrm{G}^{\circ}$ at all temperatures and all initial HA concentrations indicate the viability of the adsorption of HA onto $\mathrm{Fe}_{3} \mathrm{O}_{4}$ and the spontaneous process of the adsorption. Negative $\Delta \mathrm{H}^{\circ}$ values at all initial $\mathrm{HA}$ concentrations indicate the exothermic of the adsorption behaver, and also its magnitude gives information on the type of adsorption, which can be either physical or chemical [33]. In fact, if $\Delta \mathrm{H}^{\circ}$ is comprised between -120 and -40 $\mathrm{kJ} . \mathrm{mol}^{-1}$, the uptake process occurred mainly by chemical bonding [34], [35]. However, the value of $\Delta \mathrm{H}^{\circ}$ obtained by the present work is $-21,722 \mathrm{~kJ} \cdot \mathrm{mol}^{-1}$, showing that adsorption process of $\mathrm{HA}$ onto $\mathrm{Fe}_{3} \mathrm{O}_{4}$ was taken place mostly via physisorption mechanism. The negative values of $\Delta \mathrm{S}^{\circ}$ indicate a decrease of the chaos at solid-solution interface during the adsorption process of HA onto $\mathrm{Fe}_{3} \mathrm{O}_{4}$ [32]. This can be explained by a decrease of free sites on the adsorbent area.

\section{CONCLUSION}

Magnetite $\left(\mathrm{Fe}_{3} \mathrm{O}_{4}\right)$ was successfully prepared by chemical co-precipitation process. The HA adsorption capacities for $\mathrm{Fe} 3 \mathrm{O} 4$ increase with an increase in solution $\mathrm{pH}$ from 4 to 11 and are favored for increasing contact time and initial HA concentration. The adsorption kinetic of $\mathrm{HA}$ onto $\mathrm{Fe}_{3} \mathrm{O}_{4}$ obey a pseudo-second-order model. The equilibrium adsorption data of HA onto $\mathrm{Fe}_{3} \mathrm{O}_{4}$ fits better with Temkin isotherm model than Langmuir and Freundlich isotherms model. Thermodynamic parameters indicate the adsorption of HA onto $\mathrm{Fe}_{3} \mathrm{O}_{4}$ is spontaneous and exothermic in nature. The mechanism for the adsorption seems carried out via physisorption according to thermodynamic results. It involves electrostatic interaction and hydrogen bonding. However, chimisorption mechanism could occur but with less importance. Results of this work show that $\mathrm{Fe}_{3} \mathrm{O}_{4}$ is a promising adsorbent for removing HA from aqueous solution.

\section{REFERENCES}

[1] H. El Ghandoor, H. M. Zidan, M. Khalil, M. I. M. Ismail, Synthesis and some physical properties of magnetite (Fe3O4) nanoparticles, Int. J. Electrochem. Sci. 2012 (7), 5734-5745.

[2] L. Blaney, Magnetite (Fe3O4): Properties, Synthesis, and Applications, Lehigh Review. 2007 (15), 1-50.

[3] M. C. Mascolo, Y. Pei, T. A. Ring, Room temperature coprecipitation synthesis of magnetite nanoparticles in a large $\mathrm{pH}$ window with different bases, Materials. 2013 (6), 5549-5567.

[4] O. M. Lemine, K. Omri, B. Zhang, Sol gel synthesis of 8nm magnetite ( $\mathrm{Fe} 3 \mathrm{O} 4)$ nanoparticles and their magnetic properties, Superlattices and Microstructures. 2012 (52), 793-799.

[5] X. Sun, C. Zheng, F. Zhang, Y. Yang, G. Wu, A. Yu, N. Guang, Sizecontrolled synthesis of magnetite (Fe3O4) nanoparticles coated with glucose and gluconic acid a single Fe (III) precursor by a sucrose bifunctional hydrothermal method, J. Phys. Chem. C. 2009 (36), 16002-16008.

[6] S. F. Chin, S. C. Pang, C. H. Tan, Green Synthesis Nanoparticles (via thermal Decomposition Method) with controllable Size and Shape, Mater. Environ. Sci. 2011 (3), 299-302.

[7] B. Saha. S. Das, J. Saikia, G. Das, Preferential and Enhanced Adsorption of Different Dyes on Iron Oxide: A comparative Study, J. Phys. Chem. C. 2011 (115), 8024-8033.

[8] A. Ali, H. Zafar, M. Zia, Synthesis, characterization, applications and challenges of iron oxide nanoparticles, Nanotechnol. Sci. Appl. 2016 (9), 49-67.

[9] SH. Chen, Z. Yin, SL. Luo. CT. Au, X. J. Li, Preparation of magnetite $\mathrm{Fe} 3 \mathrm{O} 4 / \mathrm{SiO} 2 / \mathrm{Bi} 2 \mathrm{WO} 6$ microspheres and their application in photocatalysis, Materials Research Bulletin. 2013 (48), 725-729.

[10] S. Laurent, D. Forge, M. Port, A. Roch, C. Robic, L. Vander, R. N Muller, Magnetic iron oxide nanoparticles: synthesis, stabilization, vectorization, physicochemical characterizations and biological applications, Chem. Rev. 2008 (108), 2064-2110.

[11] S. Rajput, C. U Pittman, D. Mohan, Magnetic magnetite (Fe3O4) nanoparticle synthesis and applications for lead $(\mathrm{Pb} 2+)$ and chromium (Cr6+) removal from water, J. of col. and Inter. Sci. 2016 (468), 334346.

[12] H. Wang, A. A. Keller, K. K. Clark, Natural organic matter removal by adsorption onto magnetic permanently confined micelle arrays. Journal of Hazardous materials, 2011 (194), 156-161. 
[13] L. Liang, Adsorption and desorption of humic acid and fulvic acids on $\mathrm{SiO} 2$ particles at nano-and micro-scales, Colloids and surfaces, A 2011 (384), 126-130.

[14] K. Ghosh, M. Schnitzer, Macromolecular structures of humic substances Soil Science. 1980 (129), 266-276.

[15] Q. Tao, Z. Xu, J. Wang, F. Liu H. Wan, S. Zheng, Adsorption of humic acid to aminopropyl functionalized SBA-15, Microporous and Mesoporous Materials, 2010 (131), 177-185.

[16] H. Gallard, U. V. Gunten, Chlorination of natural organic matter: kinetics of chlorination and of THM formation, Water Research, 2002 (36), 65-74.

[17] A. Matilainen, M. Vepsalaienen, M. Sillanpaa, Natural organic matter removal by coagulation during drinking water treatment: a review, Advances in colloids interface Science, 2010 (159), 189-197.

[18] B. Bolto, D. Dixon, R. Eldridge, Ion exchange for the removal of natural organic matter, React. Funct. Poly. 2004 (60), 171-182.

[19] I. Sutzkover-Gutman, D. Hasson, R. Semiat, humic substances fouling in ultrafiltration processes, Dessalination, 2010 (261), 218-231.

[20] R. Lamsal, Comparison of advanced oxidation processes for the removal of organic natural matter, Water Research. 2011 (45), 3263 3269.

[21] S. Wang, T. Terdkiatburana, M. O. Tadé, Single of co-adsorption of heavy metals and humic acid on fly ash, Separat. Purif. Technol. 2008 (58), 353-358.

[22] C. Dong, W. Chen, C. Liu, Preparation of novel chitosan nanoparticles and its application for removal humic from aqueous solution, Appl. Surf. Sci. 2014 (292), 1067-1076.

[23] K. Gul, E. Gunes, Comparison of acid red 114 dye adsorption by $\mathrm{Fe} 3 \mathrm{O} 4$ and $\mathrm{Fe} 3 \mathrm{O} 4$ impregnated rice husk ash, J. of Nanomaterials. 2016, 1-11.

[24] P. L. Hariani, M. Faizal, R. Ridwan, M. Marsi, D. Setiabudidaya, Synthesis and properties of Fe3O4 nanoparticles by co-precpitation method to removal procion dye, Int. J. of Environ. Sci. and Devel. 2013 (4), 336-340.

[25] W.S. Wan Ngah, M.A.K.M. Hanafiah, S.S. Yong, Adsorption of humic acid from aqueous solutions on crosslinked chitosanepichlorohydrin beads: kinetics and isotherm studies, Colloids and Surfaces B. 2008 (65), 18-24.

[26] K.V. Kumar, S. Sivanesan, Selection of optimum sorption kinetics: comparison of linear and non-linear method, Journal of Hazardous Materials. 2006 (134), 277-279.

[27] C. Sheindorf, M. Rebhun, M. Sheintuch, A Freundlich-type multicomponent isotherm, J. Col. Inter. Sci. 1981 (79), 136-142.

[28] Y. Tang, H. Guo, L. Ciao, S. Yu, Synthesis of reduced graphene oxide/magnetite composites and investigation of their adsorption performance of fluoroquinolone antibiotics, Colloids and Surfaces A: Physicochem. Eng. Aspects. 2013 (424), 74-80.

[29] T. Madrakian, A. Afkhami, M. Ahmadi, Adsorption and kinetic studies of seven different organic dyes onto magnetite nanoparticles loaded tea waste and removal of them from wastewater samples, Spectrochimica Acta Part A: Molecular and Biomolecular Spectroscopy 2012 (99), 102-109.

[30] R.R. Sheha, E. Metwally, Equilibrium isotherm modeling of cesium adsorption onto magnetic materials, Journal of Hazardous Materials. 2007 (143), 354-361.

[31] S. Y. Yoon, C. G. Lee, J. A. Park, Kinetic, equilibrium and thermodynamic studies for phosphate adsorption to magnetic iron oxide nanoparticles, Chemical Engineering Journal. 2014 (236), 341 347.

[32] B. Tanhaei, A. Ayati. M. Lahtinen, Preparation and characterization of a novel chitosan/A12O3/magnetite nanoparticles composite adsorbent for kinetic, thermodynamic and isotherm studies of Methyl Orange adsorption, Chemical Engineering Journal. 2015 (259), 1-10.

[33] A. Ben Dekhil, M. Smiri, A. Hafiane, Kinectic, thermodynamic and structural study of the biosorption of lead and cadmium by red macroalga (Cermamium virgatum), Journal of the Tunisian chemical society. 2017 (19), 381-390.

[34] S. Chatterjee, S. H. Woo, The removal of nitrate from aqueous solutions by chitosan hydrogel beads. J. Hazard. Mater., 2009 (164) 1012-1018.

[35] M. Alkan, Ö. Demirbaş, S. Çelikçapa, M. Doğan,, Sorption of acid red 57 from aqueous solution onto sepiolite. J. Hazard. Mater., 2004 (B116) 135-145.

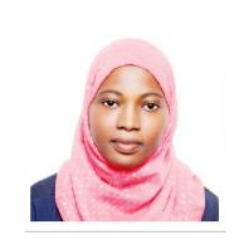

Fatou Guey is Ph.D student, Department of chemistry in Tunis El Manar University, Laboratory of Water, Membranes and Environment Biotechnology (LEMBE) Tunisia

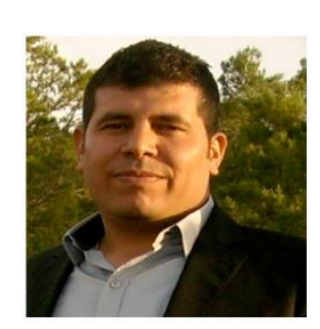

Moêz Smiri holds an M.Sc in Environmental Sciences and a $\mathrm{PhD}$ in Biological Sciences from the University of Carthage, Tunisia. His $\mathrm{PhD}$ thesis research was carried out between 2007 and 2011 on the seed development dormancy and germination. He works for FSB (Faculty of Sciences of Bizerte, Tunisia) during the period 2006-2011 and for the Faculty of Sciences and Technologies (FST) of Nancy, the University of Lorraine, France between 2007 and 2011. He is currently posted at Shaqra University, College of Science and Arts - Sagir, Saudi Arabia, since 2019. He worked for ISSTE (Higher Institute of Sciences and Technology of Environment, Tunisia), between 2012 and 2019. Since 2014 he has led a team at Laboratory of Wastewater Treatment, Center of Researches and Water Technologies (CERTE) that has developed and implemented analyses of the water resources, domestic wastewater, agricultural use and impact on seed germination and plant growth. He has 14 years of experience researching seeds, in particular leguminous, and 11 years of experience in the area of plant growth regulation. He has participated in food security assessments and rural development projects for 10 years. During his career, he has established research and development operations in Tunisia, France and Saudi Arabia. He is guiding number of Ph.D students, Masters and bachelor degree students.

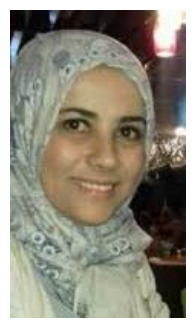

Hager Chemingui is Ph.D student, Department of chemistry in Tunis El Manar University, Laboratory of Water, Membranes and Environment Biotechnology (LEMBE) Tunisia

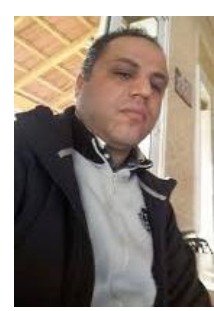

Abdelbasset Ben Dekhil is working as associate professor, Department of chemistry in Higher Institute of Sciences and Technology of Environment, Tunisia), since 2012 . He is having vast number of national and international publications. $\mathrm{He}$ is guiding number of Ph.D students , Masters and bachelor degree students.

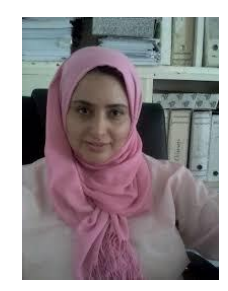

Soumaya ELARBAOUI has completed her PhD from Carthage University, Tunisia. She is a researcher in the Laboratory of Water, membrane and Biotechnology of Environnement, Tunisia. She has over 10 publications in National and International Journal, She Studied the effects of environmental and anthropological changes in marine organisms, at different levels of biological organisation, and develop valorization strategies. She is currently posted at Shaqra University, College of Science and Arts - Sagir, Saudi Arabia, since 2019.

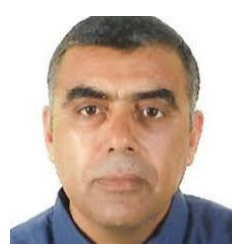

Amor Hafiane is working as Professor, Department of chemistry in The Water Researches and Technologies Center of Borj Cedria (CERTE). He is having vast number of national and international publications. He is guiding number of Ph.D students , Masters and bachelor degree students. 